\title{
O BRASIL PARA JUNTO COM AS RODAS DOS CAMINHÕES: PERSPECTIVAS DA CONTRADEMOCRACIA E SEUS LIMITES POLÍTICOS E INSTITUCIONAIS*
}

\section{THE BRAZIL STOP TOGETHER WITH TRUCK WHEELS: CONTRADEMOCRACY PROSPECTS AND ITS POLITICAL AND INSTITUTIONAL LIMITS}

\author{
ROGÉRIO GESTA LEAL
}

\begin{abstract}
RESUMO
O objetivo deste trabalho é verificar em que medida o episódio conhecido como movimento dos caminhoneiros no Brasil evidencia modalidade de participação contrademocrática e de que maneira isto coloca em xeque modelos tradicionais de democracia representativa. A justificativa desta proposta se dá pelo fato de que este movimento levou a reações aparentemente antidemocráticas por parte do governo federal, próprias de um Estado de Exceção, mas necessárias em face da periclitaçao de alguns Direitos Fundamentais Sociais. Demarcamos como problema da abordagem verificar se é possível equacionar ações politicas espontâneas e reações institucionais legais de exceção, e como hipótese a premissa de que tais ocorrências tendem a aumentar em face das crises por que passam governos e regimes democráticos, sendo indispensável pensarmos formas de composição civilizada destas tensões. A metodologia utilizada neste trabalho foi a hipotética dedutiva.
\end{abstract}

PALAVRAS-CHAVES: Democracia. Contrademocracia. Governo.

\begin{abstract}
The objective of this work is to verify to what extent the episode known as the truck-drivers movement in Brazil evidences modality of counter-democratic participation and in what way this puts in check traditional models of representative democracy. The justification for this proposal is the fact that this movement led to seemingly undemocratic reactions from the federal government, typical of Exception State, but necessary in the face of the perjury of some Social Fundamental Rights. We point out as a problem of the approach to verify if it is possible to equate spontaneous political actions and legal institutional reactions of exception, and as hypothesis the premise that such occurrences tend to increase in the face of crises that go through governments and democratic regimes, being indispensable to think forms of civilizated composition of these tensions. The methodology used in this work was the hypothetical deductive.
\end{abstract}

KEYWORDS: Democracy. CounterDemocracy. Government.

\section{NOTAS INTRODUTÓRIAS:}

O tema da Democracia em tempos como os que vivemos no Brasil é cada vez mais caro à cidadania e, por sua vez, à academia, e não somente em

* O presente artigo foi desenvolvido no âmbito do projeto de pesquisa intitulado Projeto Interinstitucional de Grupos de Pesquisa sobre o Tema Patologias Corruptivas nas Relações entre Estado, Administração Pública e Sociedade, junto à Universidade de Santa Cruz do Sul UNISC.

* Professor titular da Universidade de Santa Cruz do Sul e na Faculdade de Direito da Fundação Escola Superior do Ministério Público. Doutor em Direito pela Universidade Federal de Santa Catarina e Universidade de Buenos Aires. Desembargador do Tribunal de Justiça do Estado do Rio Grande do Sul, Titular da Quarta Câmara Criminal. E-mail: gestaleal@gmail.com. 
face dos apelos epistemológicos que ela evoca, mas fundamentalmente porque os parâmetros de constituição e operacionalização do modelo liberal, fundado na ideia de representação política pela via dos partidos politicos e eleições, tem-se mostrado insuficientes para dar conta dos níveis de complexidade e tensionalidades existentes tanto nas relações intersubjetivas como interinstitucionais.

Novos paradigmas democráticos, em face disto, são pensados e experimentados em todo o mundo, em especial os que ampliam a participação/ deliberação social no espaço publico - que igualmente tem sido redefinido para além do Estado -, do que decorrem inéditas expressões da soberania popular, dentre as quais queremos dar destaque a chamada Greve dos Caminhoneiros, ocorrida no Brasil no mês de maio deste ano de 2018, tendo - de certa forma - paralisado vários setores econômicos e políticos nacionais, com impactos violentos na vida das pessoas em todo o território nacional, assim como as medidas de exceção adotadas pelo governo federal por conta deste movimento.

Com esta compreensão ampliada e problemática da Democracia, queremos sustentar que é possível constituirmos outros pactos de legitimação das ações politicas com inclusão social profunda, a despeito dos riscos e perigos que, por vezes, isto possa implicar, inclusive envolvendo tomada de decisões de exceção que desafiam a própria Democracia.

\section{A GREVE DOS CAMINHONEIROS COMO ESPÉCIE DE AÇÃO POLÍTICA:}

Desde a segunda semana de maio de 2018 assistimos o governo brasileiro refém de movimento nacional de caminhoneiros que paralisaram, em parte, a distribuição de vários produtos essenciais ao abastecimento de mercados, hospitais, postos de combustível, gaz, dentre tantos outros, fazendo com que a Sociedade como um todo restasse desatendida em demandas fundamentais do seu cotidiano.

Iniciado como articulação e protesto de caminhoneiros, sindicalizados e autônomos, localizados no sul do país, foram ganhando corpo suas reivindicações e a elas foram se somando representações sindicais de motoristas e transporte ${ }^{1}$, gerando, em todo o território nacional, bloqueios de estradas e represamento de cargas inteiras que acabaram afetando indústria, comércio e milhares de pessoas forma impressionante.

A despeito destes cenários econômicos agudos, criados em menos de duas semanas, a greve dos caminhoneiros esteve inicialmente pautada pelas

1 Como a Confederação Nacional dos Transportadores Autônomos (CNTA), que agrupa vários sindicatos de motoristas autônomos, além da Associação Brasileira de Caminhoneiros (Abcam) e a União Nacional dos Caminhoneiros do Brasil (Unicam). Conforme https://pleno.news/ brasil/entenda-as-reivindicacoes-dos-caminhoneiros.html, acesso em 29/05/2018. 
reivindicações dos seguintes temas: (a) redução no preço do óleo diesel, já que os motoristas consideravam que o preço atual inviabiliza o transporte de mercadorias no país, realizado principalmente por rodovias; (b) que o governo alterasse a regra de reajustes no preço dos produtos, que atualmente varia dependendo das cotações internacionais; (c) o fim das alíquotas de PIS (Programa de Intervenção Social), e de Cofins (Contribuição para o Orçamento da Seguridade Social), assim como a isenção da Cide para transportadores autônomos; (d) a redução de pedágios em caso de eixos dos veículos estarem suspensos; (e) a criação de marco regulatório para os caminhoneiros; (f) a aprovação de projeto de lei que estabelece preços mínimos para o frete; (g) a criação de sistema que ofereça subsídios na aquisição de óleo diesel pelos transportadores autônomos; (h) a criação de fundo de amparo ao transportador autônomo. ${ }^{2}$

Depois de esboçar certa resistência, inclusive criando situações autorizadoras de intervenção das forças armadas para o reestabelecimento do abastecimentos de produtos e gêneros indispensáveis a população ${ }^{3}$, o governo cedeu e atendeu, em grande parte, as reivindicações do movimento, em especial com as Medidas Provisórias: (1) MP 831/2018, reservando 30\% do frete contratado pela Companhia Nacional de Abastecimento (Conab) para cooperativas de transporte autônomo, sindicatos e associações de autônomos, sendo que os transportadores passariam nesta condição a serem contratados sem licitação; (2) MP 832/2018, instituindo a Política de Preços Mínimos do Transporte Rodoviário de Cargas, para promover condições razoáveis à contratação por fretes no território nacional; (3) MP 833/2018, alterando a Lei dos Motoristas (Lei 13.103/2015) para estender para as rodovias estaduais, distritais e municipais, a dispensa de pagamento de pedágio do eixo suspenso de caminhões. Além disto, o governo federal anunciou a redução de R \$ 0,46 no preço do litro do diesel por 60 dias. $^{4}$

2 Idem. A Folha de São Paulo, em matéria veiculada no dia 27/05/2018, informou que, já no dia 21 de maio, havia 17 Estados com bloqueios de caminhões, e que a Associação Brasileira de Caminhoneiros (Abcam) se declarou organizadora do movimento, mas muitos caminhoneiros sem sindicalização aderiram à manifestação espontaneamente, via grupos de whasapp. A mesma matéria dá conta de que no dia 26/05/2018, sábado, a policia rodoviária federal informava existirem 596 pontos de manifestação em todo o país, deixando sem combustível 13 aeroportos importantes em todo o território. In www1.folha.uol.com.br, acesso em 01/06/2018.

3 O governo decretou, a pedido do comando do Exército, a edição de decreto de Garantia da Lei e da Ordem (GLO) que amparava a atuação das Forças Armadas em todo o território nacional para liberar rodoviais bloqueadas pela greve dos caminhoneiros, o que, aliás, foi muito bem conduzido, haja vista os altos índices de sucesso das composições pacificas alcançadas às liberações das estradas. Imaginava o governo que inclusive poderia surgir a necessidade de se valer da requisição de bens e produtos para a retomada do abastecimento, consoante autorição da Constituição Federal, em seu art.5, inciso XXV. Veja-se as noticias no site http://www. gazetadopovo.com.br/politica/republica/decreto-de-glo-autoriza-uso-de-militares-contragreve-dos-caminhoneiros-4qi15m8d1uhik8ydnd6e00zzz, acesso em 01/06/2018.

4 Conforme nota no site https:/www12.senado.leg.br/noticias/materias/2018/05/28/ 
Os significados políticos, institucionais e jurídicos destes episódios estão sendo demarcados em profusão neste momento, e um deles entendemos que seja o de indicar a fragilidade temporal e espacial do Poder Executivo brasileiro em lidar com demandas emergenciais, ações e protagonismos políticos inéditos, sendo preciso compreender de maneira amplidada que fenômenos são estes, com seus aspectos positivos e negativos, que é o que passamos a fazer.

\section{A DEMOCRACIA E SUAS POSSÍVEIS TRANSFORMAÇÕES:}

Nos últimos anos temos visto ocorrer muitas transformações sociais, políticas, institucionais e econômicas altamente complexas e multifacetadas, envolvendo inclusive mudanças de paradigmas morais e éticos de pessoas físicas e jurídicas, o que tem provocado alterações normativas e de políticas públicas por parte dos Estados Democráticos de Direito, ora para tentar conter estes processos, que nem sempre são benignos (o que se dá em vão), ora para estabelecer responsabilidades pelos danos que eles causam em seus movimentos não lineares, ora ainda para acolmatá-los na práxis ordinária das relações sociais lícitas.

Estes cenários fazem com que não possamos mais utilizar conceitos e fórmulas acabadas de modelos democráticos antigos - e mesmo modernos para compreender de maneira adequada e oxigenada as causas e consequencias decorrentes daí. Tampouco tem sido fácil estruturar minimamente arquiteturas institucionais que recepcionem e atendam satisfatoriamente as demandas individuais e sociais que exsurgem hodiernamente, seja decorrentes de representações mais tradicionais dos diversos segmentos sociais (partidos políticos e setores econômicos organizados), seja oriundas de articulações espontâneas de massa, notadamente marcadas muito mais por pautas negativas de protestos do que por agendas propositivas em termos de alternativas governamentais ou de políticas públicas.

Isto ocorre não só em face daquelas demandas possuirem morfologias mutantes (ambientais, de consumo, de segurança pública) provocadas pelos riscos e perigos que lhes dão causa, mas também porque elas reclamam respostas criativas e inovadoras em termos de prevenção e atribuição de responsabilidades efetivas.

Quando os governos - Legislativo e Executivo - não conseguem prevenir/ evitar/resolver conflitos decorrentes destes cenários, ambientes tensos e violentos podem se constituir, alguns como forma de reação/resistência de interlocutores políticos institucionais (exército), ou não institucionais (sociedade); outros, como forma de ataque ao poder instituído (revolução, guerra civil). Em ambas as situações o sistema jurídico sofre abalos sísmicos desestruturantes, a ponto

congresso-recebe-medidas-provisorias-do-acordo-do-governo-com-caminhoneiros, acesso em 01/06/2018. 
de, em determinadas circunstâncias, impor-se suspensões a vigência e a eficácia de algumas normas deste sistema. Ai estaríamos em face do Estado de Exceção.

Agamben sustenta que este modelo de Estado não se configura como ditadura constitucional ou inconstitucional, comissarial ou soberana, mas tão somente como espaço vazio de Direito, zona de anomia em que todas as determinações jurídicas são parcial ou totalmente desativadas, assim como as distinções entre espaço público e privado. ${ }^{5}$ Mas esta possibilidade de anomia no constitucionalismo contemporâneo - e em especial no Brasileiro-, tem de ser controlada minimamente pelo sistema normativo (como no Estado de Sítio, nos termos do art.136 e 137, da Constituição Federal de 1988), sob pena de, ai sim, termos riscos maiores a situações excepcionais de autoritarismo. ${ }^{6} \mathrm{Ou}$ seja, mesmo em ambiente de emergência/exceção, a história nos ensinou que devemos ter, ao menos, parâmetros objetivos/normativos para lidar com ela, principalmente no que diz com procedimentos e responsabilidades decorrentes do seu enfrentamento.

Claro que em tais cenários de urgências há níveis igualmente diferidos de usos de subjetividades decisionais dos agentes públicos e privados que se encontram atingidos, mas que contam, pela via do plano normativo vigente, ao menos com elementos de aferição e julgamento no que tange às justificações e fundamentos dos atos e fatos efetivados, assim como as suas consequências.

Sem sombra de duvidas que, por outro lado, dinâmicas de riscos e perigos que assolam cada vez mais nosso cotidiano (surtos de patologias letais, como dengue, malária, zica; desabamentos de núcleos habitacionais; enchentes e incêndios), têm incrementado alguns protagonismos institucionais assimétricos, como é o caso da expansão do Poder Executivo, que para dar conta destas demandas precisa agir rápido (urgência/emergência), não tendo condições de aguardar determinados procedimentos próprios da Democracia Representativa, como aprovação de leis e outras medidas pelo Parlamento, sob pena de agravar as consequências daquelas ocorrências.

O problema é quando formas de gestão pública para o tratamento de emergências trágicas se transformam em métodos ordinários de gerenciamento de demandas normais da comunidade, provocando o que podemos chamar de banalização da exceção. ${ }^{7}$ Em outras palavras, também contando com processos

5 AGAMBEN, Giorgio. Stato di eccezione. Homo sacer, II, I. Torino: Bollati Boringhieri editore, 2003, p.75. Faz referência o autor ao debate entre Carl Schmitt e Walter Benjamin sobre estes temas.

6 Esta a advertência de SCHMITT, Carl. Teologia Política. In A crise da democracia parlamentar. São Paulo: Scritta, 1996, ao asseverar que, a despeito do Estado de Excepção configurar certo tipo de violência que não possui normas suficientes para dar conta de suas causas e efeitos (anomia), a anomia deve ser inscrita no corpo do sistema jurídico (nomos), pois não pode haver violência pura fora do Direito em Estados Constitucionais.

7 Ver o texto de CEDRONIO, Marina (ed.). Modernité, Démocratie et Totalitarisme: Simone Weil et Hannah Arendt. París: Klincksieck, 1996. 
de atrofia do Parlamento, retroalimentados por políticas de coalizões fundadas em escambo de interesses mais pessoais/corporativos do que públicos, o Poder Executivo vai criando hábitos decisionais pautados por agendas e prioridades constituídas a partir de suas avaliações/escopos endógenos, geralmente associados a interesses muito segmentados da Sociedade e do Mercado. ${ }^{8}$

Para além disto, em regra, aquelas decisões de urgência do Poder Executivo, por operarem em zonas jurídicas ambíguas e incertas, passam por filtros preventivos de legitimidade e legalidade muito deficitários, o que amplia as possibilidades de incorrerem em abusos de autoridade e/ou desvios de poder.

Quando o excepcional se torna ordinário, a hipótese de suspensão do sistema jurídico se transforma em algo muito complicado, pois ela não implica sua abolição, mas a vigência deste sistema tampouco implica sua eficácia. Por conta disto, neste limbo em que a não abolição da norma em vigor resta indeterminada pela sua não eficácia, a força da lei é ficticiamente cooptada por medidas de urgência - Decretos-Leis, Medidas Provisórias, politicas públicas, formas de gestão centralizadas - que se eternizam no tempo e espaço (transmutação da ordinariedade), cujos níveis de legitimidade democrática podem ser (ou não) questionados de forma direta (controle interno e externo dos atos normativos), e indireta (crítica social pelas mídias ou por movimentos de massa contestativos). ${ }^{9}$

Destas ambiências é que surgem elementos novos à Democracia e à Política, alguns até em rota de colisão em termos de processos constitutivos e mesmo consequências. Assim, para o que nos interessa nesta abordagem, duas consequências (nada paradoxais) - dentre outras - se formatam: (1) o movimento dos caminhoneiros como exercício do direito fundamental de ação e participação política democrática, a partir de inovadores mecanismos de interlocução política entre espaço público e privado, os quais identificam níveis agudos de deslegitimação da representação politica em geral (Legislativo e Executivo); (2) o risco de desabastecimento de produtos essenciais a dignidade humana da população, por decorrência do movimento dos caminhoneiros, gera modulações de Estado de Exceção, pela via de medidas de exceção/urgência/ emergência por parte do Governo/Estado, como a institucionalização da Garantia da Lei e da Ordem - GLO.

8 Michel Foucault discute isto em torno da questão do biopoder e das diversas formas pelas quais se instala normalmente, na vida cotidiana, os saberes e verdades instituídos. Ver FOUCAULT, Michel. Verdad y Poder. Obras esenciales. Madrid: Paidós, 2010, pp. 379-391. Ver também o excelente texto de LIMONGI, Fernando e FIGUEIREDO, Argelina. Bases institucionais do Presidencialismo de Coalizão. In Lua Nova, no 44, p. 81-106, 1998.

9 Lembremos de Hitler que manteve vigente a Constituição de Weimar suspendendo as normas referente as liberdades pessoais em face do argumento do Estado de Exceção que se extendeu por 12 anos (1933/1945), constituindo verdadeiro paradoxo diante de um Estado que contava com Constituição formalmente democrática convivendo com gestão pública de emergência e violenta. 
Passemos a breve analise destes fenômenos.

\section{O MOVIMENTO DOS CAMINHONEIROS COMO EXERCÍCIO DO DIREITO FUNDAMENTAL DE AÇÃO E PARTICIPAÇÃO POLÍTICA DEMOCRÁTICA.}

Lembrando Ulrich K. Preuss, temos que a incumbência dos negócios públicos não pode ser sustentada pela lógica de que devem por eles responder somente as pessoas que detém mais posses, riquezas, prestígio, tradição, e isto porque todos os indivíduos valorosos por seus compromissos com a comunidade (cidadãos) estão aptos a desenvolver atividades de gestão dos interesses comunitários. ${ }^{10}$

Daí conseguimos constituir certa convergência para o fato de que qualquer conceito de cidadão ou cidadania deve ser sempre situado como sujeito histórico, e enquanto tal, desde os albores da Idade Moderna, ao menos no Ocidente, tem alcançado e desenvolvido protagonismos político e jurídico sem precedentes, mesmo em Estados Nacionais totalitários que se forjaram desde então, atingindo hoje a condição que Preuss chama de cidadão da terra (global). ${ }^{11}$ Com tal importância, ao mesmo tempo, este cidadão vê ampliados seus direitos e prerrogativas constitucionais, e seus deveres constitucionais, já que figura como co-responsável - no modelo de democracia representativa pela constituição da sua própria história e as formas (normativas e fáticas) a partir das quais ela se desenvolve. ${ }^{12}$

10 PREUSS, Urlich K. The ambiguous meaning of citizenship. Trabalho apresentado na University of Chicago Law School, no Center for Comparative Constitutionalism, em dezembro de 2006. Acessado em www.universityofchicago/lawschool/papers, em 20/10/2008. Diz textualmente o autor: At one point in human history somebody had the idea that the handling of the affairs of his community was not necessarily incumbent upon the big landowners, the wealthy, the military leaders or the heads of the most powerful tribes, clans, and families, in other words: upon the 'natural' masters of the community; rather, the survival and the well-being of the community might be better served if its matters were conducted by a class of individuals who due to their personal qualities and resources were valuable for the community as a whole. This was the birth of the idea of citizenship. Na mesma direção ver o texto de RIESENBERG, Peter. Citizenship in the Western Tradition. Plato to Rousseau. Chapel Hill/London: The University of North Carolina Press, 2000.

11 Refere textualmente o autor: Even in the modern absolutist state which emerged in the 17th century citizenship had not been entirely abolished and forgotten. Its persisting timeliness can be viewed from the fact that the European Union has recently created the new status of European citizenship (more precisely: Union citizenship) and that, moreover, even the 18th century-idea of humankind and cosmopolitism has now found its current equivalence in the notion of 'earth citizenship. PREUSS, Urlich K. The ambiguous meaning of citizenship. Op.cit., p.02.

12 E no plano da Teoria Política, não há nada de novo aqui, haja vista ser este o conceito formal de cidadania apresentado por ARISTÓTELES. Politics. New York: Basic Books, 2000, p.16: The good citizen should know and have the capacity both to rule and to be ruled, and this very thing is the virtue of a citizen. É óbvio que temos de ter presente a dimensão material deste conceito no tempo e espaço de Aristóteles, uma vez que The Aristotelian "capacity" to rule was a matter of status, not of ability, no sentido de que esta capacidade estava ligada às questões do poder material e monárquico existentes. Em face disto, in fact, throughout the history of 
Por estas razões é que Pocock sustenta que o sentido da ideia de cidadania hoje restaurado representa verdadeira new social construction of a "we". It is a very specific "we", not just one which gives expression to any kind of belonging which also families or tribes develop. It is a "we" based on the sense of equality, symmetric mutuality and responsibility for the community as such. Essentially citizenship means a status of duties and rights ${ }^{13}$.

Mas quais os veículos, formas e possibilidades de participação/ação politica da cidadania na Democracia (e no Estado Democrático de Direito) então?

Para nós esta questão só pode ser respondida tendo em conta, como quer Habermas já no final da década de 50, que a cidadania e a Democracia devem ser definidas processualmente e substancialmente como processos históricos, e neles elemento chave é a formatação de espaço público em que a Sociedade possa assumir sua condição de protagonista da história, a partir de instrumentos efetivos de comunicação e decisão procedimentalmente inclusiva de todos os interessados e atingidos pelas medidas a serem adotadas. ${ }^{14}$ Por certo que isto, todavia, não é possível em modelos de organização social, política e econômica nos quais partidos, pessoas físicas e jurídicas tomam de assalto o Estado para o atendimento de interesses muito mais corporativos do que comuntários cenário muito próprio do brasileiro. ${ }^{15}$

E quando estas condições democráticas da ação política não ocorrem, o que temos é a perda da credibilidade/confiança nos modelos desta ação, dando vezo, como quer Rosanvallon, a no mínimo duas reações no espaço público: (i) multiplicam-se propostas e experiências que buscam reforçar condicionantes de legitimidade procedimental, como iniciativas envolvendo reações mais integradas e em rede de instituições tradicionais do Mercado, Sociedade Civil e Estado (Parlamento, Judiciário, Associações Empresariais, Sindicatos); (ii) surge o entrecruzamento de práticas de contrapoderes sociais informais destinadas a compensar a erosão da confiança mediante a organização propositiva da desconfiança. ${ }^{16}$

ancient Greek citizenship the citizens were always a minority. On no account did they rule only themselves. They ruled over the great bulk of non-citizens: slaves, women, children, metics, aliens and other categories of individuals who lived within the physical boundaries of Attica, conforme WALZER, Michael. Thinking Politically: essays in political theory. New York: Vail Ballou Press, 2007, p.36.

13 POCOCK, Jonh Arthur. Theorizing Citizenship. New York: State University of New York Press, 2004, p. 29. Grifo nosso.

14 HABERMAS, Jürgen. Su concetto di partecipazione politica. Roma: Daltrice, 2000, p.11.

15 Em tais circunstâncias, la sfera pubblica non esiste, poichè essa non è più una sfera pubblica politica, ma è fondamentalmente, si potrebbe dire con parole nostre, una sfera econômicocorporativa, e, portanto, sarebbe necessario il passaggio a una democrazia non solo politica, ovvero um controllo politico del potere sociale. Idem, p.15.

16 ROSANVALLON, Pierre. Le contre-démocratie: la politique à l'âge de la défiance. Paris: Le Seuil, 2006, p.22. Rosanvallon lembra que o tema da desconfiança sempre esteve presente do 
De certa forma esta segunda reação referida caracteriza o episódio da greve dos caminhoneiros enquanto forma de contrademocracia disseminada em segmentos sociais não institucionalizados que são capazes de ordenar movimentos de ação/reação tópicos em face do desgoverno e da deslegitimidade dos poderes instituídos à representação e decisões politicas, provocando tensões e conflitos (lícitos e ilícitos) que merecem processamentos e respostas adequadas, a partir dos quais podemos ter momentos de emancipação e efetivação de direitos e garantias, individuais e sociais.

Entretanto, cumpre reconhecermos, como todo movimento político espontâneo, que as chances de desvio de finalidade são muito grandes, o que efetivamente ocorreu na greve dos caminhoneiros com o passar do tempo, ao menos em parte, conforme se vê do informe seguinte:

Como um filme repetido, já rodado nas manifestações de junho de 2013, a greve dos caminhoneiros começou com pauta específica, cresceu com o apoio popular, mas a adesão de diversos grupos ao movimento e a inclusão de temas alheios ao debate original transformou a paralisação em uma massa confusa e sem controle.

Lideres de entidades que deflagraram a greve dizem que ela terminou, mas veículos de autônomos seguem parados nas rodovias e dezenas de grupos de extrema-direita se arvoram a pedir intervenção militar, eufemismo para ditadura.

- A mobilização da categoria está encerrada. A pauta de negociação foi cumprida. No domingo, tivemos um dia histórico ao conseguirmos medida provisória para estabelecer o piso mínimo do frete. Isso é um pedido que temos desde 1999. O que restou hoje (da greve) é um movimento político. Se somaram outras pautas que não são as do setor. É a intervenção militar, o Fora Temer, o Lula Livre, a sociedade indignada com o conjunto disso tudo. Isso foi para dentro dos piquetes - diz Carlos Alberto Litti Dahmer, presidente do Sindicato dos Transportadores Autônomos de Cargas de Ijuí. ${ }^{17}$

Mas estes processos não podem ser tomados como patológicos do fenômeno político contemporâneo, justamente porque, de um lado, (a) há dimensões das ações políticas inviáveis de serem controladas em termos causas e consequências; por outro, (b) alguns destes processos nascem de determinadas demandas e conflitos, mas, por conta de sinergias e confluências que se constituem em redes e protagonismos múltiplos, dispersos no tecido social, vão

debate político do Liberalismo, desde Madison até Bejamin Constant (só para falar de dois precursores), no sentido de que o Poder deve conter o Poder, e por isto ele deveria ser débil, constantemente submetido a suspeita, e esta desconfiança não é a melhor à Democracia, pois esta reclama velar-se para que o Poder seja fiel aos seus compromissos com o bem comum. Ver também o texto de ARROW, Kenneth J. The limits of organization. New York: Norton, 1974.

17 https://gauchazh.clicrbs.com.br/ultimas-noticias/tag/greve-dos-caminhoneiros/, acesso em 29/05/2018. Ainda informa o site que: a greve dos caminhoneiros entra no nono dia nesta terçafeira (29) com registros de manifestações em diversos pontos do Rio Grande do Sul. De acordo com Federação das Indústria do Estado do Rio Grande do Sul (Fiergs), o prejuízo da mobilização para as fábricas chega, até agora, a R \$1,6 bilhão. Os segmentos de bebidas, laticínios e alimentos são os mais prejudicados, mas também há impactos nas áreas químicas, veículos e máquinas. 
interagindo e se fundindo com outros a partir de pontos de conexões variáveis, isto é: Se somaram outras pautas que não são as do setor. É a intervenção militar, o Fora Temer, o Lula Livre, a sociedade indignada com o conjunto disso tudo. Isso foi para dentro dos piquetes. ${ }^{18}$

Diante destes desdobramentos (e não devios) de situações imprevisíveis surgiu um problema para a gestão pública que é como mediar o exercício legitimo da contra-democracia e o risco de desabastecimento de gêneros e demandas de natureza vital da população! E aqui se destacou a questão da decisão política em ambientes de exceção, aspecto que temos de considerar em particular - sob o prisma teórico e prático -, dada sua importância transcendental à compreensão do tema proposto neste trabalho.

\section{QUAL DECISÃO POLÍTICA EM AMBIENTES DE EXCEÇÃO É DEMOCRÁTICA?}

Sob o ponto de vista filosófico, o ensaio Teologia Política, de Carl Schmitt, traz vários elementos que são muito caros ao debate que pretendemos neste texto, principalmente quando consideramos os quatro capítulos que lá se encontram sobre: (i) a definição de seberania, (ii) o problema desta soberania enquanto forma jurídica e decisória, (iii) a teologia política, e (iv) a filosofia do Estado da contrarrevolução, sendo que os dois primeiros se centram sobre a definição dos conceitos de soberania, exceção e decisão, enquanto que os outros dois fornecem uma sociologia do conceito de soberania e espõem o teorema schmittiano da Modernidade como secularização. ${ }^{19}$

Sob a perspectiva da teoria shcmittiana da Democracia, o capitulo sobre teologia política é importante sob, no mínimo, dois pontos de vista: (i) em face da construção que faz o autor do conceito soberania-exceção-decisão, já demarcando sua compreensão do Estado Absoluto (fundado na soberania do monarca), e do Estado Democrático (fundado na soberania do povo). Aqui Schmitt constrói um paralelismo entre a reação ao positivismo jurídico formalístico que se realiza em especial no âmbito do direito civil, e aquela que se encontra no âmbito do direito público, propondo uma interpretação do conceito de exceção como lacuna constitucional que está presente na base das constituições democráticas tomadas como ordenamentos incompletos. (ii) De outro lado, levando em conta o teorema schmittiano da Modernidade como secularização do teológico no político, em dois sentidos diversos - como conservação ou como neutralização (permitindo-lhe analisar a relação da Democracia com a transcendência e a imanência).

18 Idem.

19 SCHMITT, Carl. Teologia Política. In A crise da democracia parlamentar. Op.cit. 
A proposta da prioridade do Estado sobre a Constituição feita por Schmitt sustenta que o Estado é a casa solidamente construída, enquanto que a Constituição - em relação a esta casa - representa algo que lhe aprimora, um luxo que se pode permitir somente a quem já possui uma casa sólida. ${ }^{20}$

Dai porque o decisionismo schmittiano pode ser interpretado como a chave de leitura da gênese, do desenvolvimento e da crise da mediação racional moderna envolvendo relações politicas e sociais, enquanto parte da teoria constitucional desenvolvida pelo autor em 1928, em contraste à Teoria Geral do Estado mais tradicional vigente em sua época (em especial a kelseniana). ${ }^{21}$ A crise referida diz com o reconhecimento de que a decisão em ambientes de exceção pode ser considerada como atinente as lacunas na constituição do Estado, fundamentalmente em face do reconhecimento de que a definição jurídica deste não dá conta das complexidades que materialmente fazem parte de seu cotidiano, evidenciando que o elemento jurídico definidor do Estado não dá vazão adequada ao político e suas intermitências, impondo tomada de decisões que, por vezes, não se enquadram na moldura do sistema jurídico demarcador de determinado modelo de Estado.

Lembremos que esta interpretação da exceção como lacuna da Constituição e do Estado encontra guarida no inicio da teologia politica schmittiana, eis que o autor alemão enfrenta o problema da competência sobre quem deve decidir na presença de extremus necessitatis casus - que na Constituição de Weimar de 1919, no seu art.48, é o Presidente da República. Assim, para Schmitt, a disputa em torno do problema da soberania não diz respeito a definição do seu conceito em si, mas do seu concreto exercício pelo soberano, que é ilimitado naquelas situações excepcionais. $^{22}$

Esta característica de poder excepcional ilimitado em face de situações urgentes e excepcionais criam aparente justificativa racional para a constituição de determinado tipo de poder e seu exercício, pois justamente precisa enfrentar cenários imprevisíveis e indescritíveis sob o plano normativo - dai que excepcionais. Assim,

l'eccezione, non essendo descrivibile, è la lacuna, sempre possibile, che si apre nell'ordinamento costituzionale; non si puo pertanto cercare nel testo costituzionale la normativa per stabilire quando un'eccezione si verifichi effettivamente. L'illimitatezza del contenuto della competenza è una conseguenza della indescrivibilità, ovvero della concretezza, dell'eccezione:

20 Ver o texto de TAYLOR, Alan John P. Bismarck: The Man and the Statesman. New York: Vintage Books, 1967, p.39.

21 Ver o excelente texto de GALLI, Carlo. Genealogia della politica: Carl Schmitt e la crisi del pensiero politico moderno. Bologna: Mulino, 1996.

22 Ver o texto de BARBIERI, Maria Stella. Il senso del politico. Saggio su Carl Schmitt. Milano: Giuffrè, 1990. Ver também o texto de BEAUD, Oliver. La potenza dello Stato. Napoli: Edizioni Scientifiche Italiane, 2002. 
l'ordinamento giuridico vigente non può prescrivere quali misure debbano concretamente essere prese per far fronte all'emergenza. ${ }^{23}$

Este o argumento central de Schmitt, no sentido de que o Estado de Exceção não pode ser regulado totalmente porque as situações excepcionais não podem ser previstas de maneira absoluta, escapando de determinações gerais, razão pela qual há dificuldades de serem encontradas normas suficientes para serem aplicadas a elas. E nestas situações de anomias normativas o que temos de mais relevante são as tomadas de decisões (politicas) de exceção pelas autoridades competentes (soberano) - não raro de forma e modo monocrático. ${ }^{24}$

Por outro lado, experiências de exceção - não raro - geram espaços de indeterminação politica e jurídica; vazios de direito que são aproveitados para que a exceção mesma, e os poderes que se beneficiam com ela, se perpetuem no tempo e no espaço, e mesmo fomentem processos de tolerância e assimilação alienada de culturas e práticas autoritárias. Esta exceção como indeterminação vai se transformando, de maneira usual, em técnica de governo que usurpa dos demais protagonistas e responsáveis pela Democracia a oportunidade/direito/ dever de decisão.

Em verdade, a experiência concreta de países como o Brasil tem nos demonstrado que as medidas de exceção usualmente funcionam em zonas ambíguas e incertas, nas quais certas decisões não se amoldam perfeitamente - e até por vezes se divorciam - de regras e princípios jurídicos vigentes e vinculantes. Como diz Agamben, estes limbos gerados e reiterados pela excepcionalidade fazem com que os fatos regulados e o direito manejado se tornem, de certa forma, indecidiveis. ${ }^{25}$

E isto ocorre porque, por mais que a suspensão eventual do sistema jurídico (parcial ou total) em estados de emergência não implique sua abolição, sua vigência tampouco implica sua eficácia, criando, pois, aquele limbo referido; ou seja, a não abolição da lei em vigor nos estados de exceção provoca, de qualquer sorte, níveis de indeterminação normativa em face de sua não eficácia provocada pela suspensão operada, sendo a força da lei cooptada por medidas de exceção implantadas - decretos-leis, medidas provisórias. ${ }^{26}$

23 GALLI, Carlo. Genealogia della politica: Carl Schmitt e la crisi del pensiero politico moderno. Op.cit., p.56.

24 Aqui a ditadura comissarial schmittiana suspende temporariamente o sistema jurídico vigente com o fim de protegê-lo das ameaças da exceção. Ver o texto SCHMITT, Carl. La Dictadura. Op.cit..

25 AGAMBEN, Giorgio. Stato di eccezione. Op.cit., p.21. É muito comum, em tais situações, agravar-se a perda de especificidade entre o normal e o excepcional, tornando-se este cada vez mais ordinário, gerando inclusive processos de naturalização da suspensão material de sistemas jurídicos válidos e vigentes.

26 Ver o texto de JIMÉNEZ, Gretty Del Carmen Pavlovich. El estado de excepción: la tensión entre la politica y el derecho. In Justicia Juris, ISSN 1692-8571, Vol 10. Octubre 2008 - Marzo 2009, Pag. 37/49. 
Enfim, quais são as medidas indicadas para dar conta de problemas nunca antes experimentados, imprevisíveis? Como controlar ações e políticas voltadas para atender tais demandas, se estas sequer existiam até então, muito menos formas de regulá-las preventivamente?

As Constituições mais contemporâneas - em especial as do século XX tentaram prevenir tais problemas a partir da regulamentação/previsão genérica de situações excepcionais nas quais as tomadas de decisões precisariam ser levadas a cabo de forma urgente e imediata, portanto, não respeitando, por vezes, os tempos e modos regulamentares da ação política e governamental (processo legislativo, devido processo legal, processo administrativo regulamentar). Ai estão, a titulo de exemplo, as figuras do Estado de Sítio e Estado de Defesa, previstos nos arts.136 a 144, da Constituição Federal brasileira de 1988, os quais autorizam medidas de exceção a serem adotadas pelo Presidente da República sem observância de instâncias e procedimentos adotados em situações de normalidade.

Mas ainda assim, por serem genéricas aquelas situações, não conseguem alcançar todas as possibilidades de ocorrências que reclamam decisões emergenciais sob pena de gerar catástrofes e tragédias individuais e sociais sem precedentes.

Em meio a greve dos caminhoneiros, quando os níveis de desabastecimento de produtos essenciais a serviços públicos e demandas sociais se radicalizavam, o governo federal lançou mão de ferramenta que se assemelha ao Estado de Defesa, pois autorizou a atuação do Exército em Garantia da Lei e da Ordem (GLO). ${ }^{27}$ Tais operações da GLO ocorrem nos casos em que há esgotamento das forças tradicionais de segurança pública, em situações graves de perturbação da ordem, concedendo aos militares a faculdade de atuar com poder de polícia até o restabelecimento da normalidade. É assim que dispõe o art.3, do Decreto nr.3897/2001.:

Na hipótese de emprego das Forças Armadas para a garantia da lei e da ordem, objetivando a preservação da ordem pública e da incolumidade das pessoas e do patrimônio, porque esgotados os instrumentos a isso previstos no art. 144 da Constituição, lhes incumbirá, sempre que se faça necessário, desenvolver as ações de polícia ostensiva, como as demais, de natureza preventiva ou repressiva, que se incluem na competência, constitucional e legal, das Polícias Militares, observados os termos e limites impostos, a estas últimas, pelo ordenamento jurídico.

Parágrafo único. Consideram-se esgotados os meios previstos no art. 144 da Constituição, inclusive no que concerne às Polícias Militares, quando, em determinado momento, indisponiveis, inexistentes, ou insuficientes ao desempenho regular de sua missão constitucional.

27 Nos termos da Lei Complementar nr.97, de 1999, art.15, mais o Decreto nr.3897, de 2001. 
Pela via do Decreto nr.9.382, de 25 de maio de 2018, o governo federal instituiu a GLO para a desobstrução das vias públicas, visando objetivamente a liberação de caminhões que desejassem voltar ao trabalho, em especial para atender demandas envolvendo: a remoção ou a condução de veículos que estivessem obstruindo a via pública; escolta de veículos que prestassem serviços essenciais ou transportassem produtos considerados essenciais; a garantia de acesso a locais de produção ou distribuição de produtos considerados essenciais; e as medidas de proteção para infraestrutura considerada crítica. ${ }^{28}$

Neste período, veículos de mídia informaram que empresários solicitaram às Forças Armadas trezentos militares para dirigir caminhões que estavam parados por causa da greve de seus motoristas, eis que, no dia 29 de maio do corrente ano, computava-se que mais de mil e quinhentos militares estavam de prontidão para atender à demanda. O governo também autorizou os militares a transportar caminhões de autônomos, seja atendendo quem se sentisse acuado a aderir à greve, ou mesmo pela via da requisição de bem. ${ }^{29}$

Ou seja, estes cenários todos criaram situações emergenciais de tomada de decisões que, não raro, efetivaram-se por puro decisionismo soberano de quem estava exercendo - mesmo que com autorização normativa - o poder institucional de exceção do Estado de Direito.

\section{CONSIDERAÇÕES FINAIS:}

Ao fim e ao cabo é preciso termos claros quais os fundamentos racionais dos pressupostos que estão na base de qualquer comunicação politica que se queira democrática e emancipadora, o que envolve, como ponto de partida teórico, o que Habermas nomina de situação de fala ideal, como tentativa de interpretar procedimentos de consensos racionais constituídos no tecido social, não os relacionando com seus conteúdos propriamente ditos. ${ }^{30}$

Tal perspectiva de situação ideal de fala serve para resumir as regras para serem seguidas em argumentações morais e políticas: simetria e reciprocidade. Simetria refere-se a atos de fala, ou seja, cada participante deve ter iguais chances para iniciar e continuar a comunicação, bem como fazer afirmações, fornecer explanações e problematizar justificações. Já a reciprocidade diz com os contextos da ação, no sentido de que os participantes de quaisquer atos de fala devem ter iguais chances para expressar suas intenções, sentimentos e

28 Art.3, incisos I a IV, do Decreto nr.9.382/2018.

29 Conforme site de noticias http://politica.estadao.com.br/blogs/coluna-do-estadao/empresariospedem-e-300-militares-ja-dirigem-caminhoes-privados/, acesso em 29/05/2018. Lembrando que, o artigo 5, inciso XXV, da Constituição Federal de 1988, permite, no caso de iminente perigo público, a requisição e uso de propriedade particular, assegurada ao proprietário indenização ulterior, se houver dano.

30 HABERMAS, Jürgen. Su concetto di partecipazione politica. Op.cit. 
desejos, e os interlocutores devem agir como se cada um deles tivesse a mesma capacidade para ordenar, para prometer e ser responsável. ${ }^{31}$

Mas infelizmente não se dão desta forma as interlocuções no âmbito da política e do político modo geral (e muito especialmente no Brasil), haja vista que elas operam sempre a partir de disputas que reclamam razões/argumentos de justificação e fundamentação públicos quem nem sempre se fazem presentes, constituindo-se, em muitos casos, em face de interesses e projetos muito mais privados do que públicos, os quais, levados ao Estado Capturado pelos primeiros, transformam-se em politicas de governo sob a falácia da legitimidade das escolhas realizadas pelas autoridades representativas eleitas.

Surge deste quadro de fatores aguda crise de representação politica ferida fortemente pela erosão do capital de confiança diante dos representantes. Estes déficits de fidúcia afetam todo o jogo de relações de poder existentes, alcançando as próprias instituições de governo, eclodindo o que Rosanvallon chama de Sociedade da Desconfiança ${ }^{32}$, a qual se vê permanentemente retroalimentada por fatores como: (i) o aumento da corrupção (e o conhecimento sobre ela), ilustrada pela multiplação de denuncias e de escândalos espetacularizados pela mídia e, alguns, pelas autoridades públicas que criam teatralizações persecutórias (desproporcionais e desnecessários para os fins almejados); (ii) o contraste entre a indiferença social para com a política e a existência de práticas políticas marcadas por interesses absolutamente pessoais e regidas pela preocupação de mantença no poder. $^{33}$

Não vemos, por outro lado, estas ambiências como patológicas à Democracia contemporânea! Ao contrário, seguindo a reflexão de autores como Lefort e Rosanvallon, temos que estas crises da Democracia são fases constitutivas do (mal)funcionamento de regimes políticos contemporâneos em sociedades marcadas por riscos, perigos e complexidades os mais diversos, nas quais se dissolvem as ultimas referências às certezas de modelos simplificados

31 Interssante neste sentido a experiência ocorrida em Londres, em 2014, uma nova manifestação popular aos moldes da Ocuppy Democracy de New York, em Wall Street, nas palavras de David Graeber: A new incarnation of Occupy London has attempted to use the space for an experiment in democratic organising. The idea was to turn Parliament Square back to the purposes to which it was, by most accounts, originally created: a place for public meetings and discussions, with an eye to bringing all the issues ignored by politicians in Westminster back into public debate. Seminars and assemblies were planned, colourful bamboo towers and sound systems put in place, to be followed by a temporary library, kitchen and toilets. GRABER, David. Occupy Democracy is not considered newsworthy. It should be. In https:// www.theguardian.com/commentisfree/2014/oct/27/occupy-democracy-london-parliamentsquare, acesso em 14/08/2018.

32 Estamos falando da desconfiança democrática, que é propositiva, de controle, geradora de formas de obstrução do abuso e desvio de poder, e por isto verdadeira barreira de proteção dos interesses públicos, e não da desconfiança liberal, debilitadora do Estado enquanto espaço de gestão do público em nome de proteção radical das liberdades individais dissociadas das garantias sociais.

33 Ver o texto de CHEVALIER, Jacques. O Estado Posmoderno. Bogotá: Universidad Externado, 2015. 
de gestão de interesses públicos e privados. ${ }^{34} \mathrm{Na}$ dicção de Rosanvallon, as indeterminações e flutuações de demandas e respostas à Democracia tornam-a verdadeiro campo de experimentações que reclamam a revisão de métodos e técnicas de abordagem, compreensão e crítica da ação política, sob pena de variações da Democracia decorrentes do cansaço e da desconfiança social darem causa a modelos de Democracia do Rechaço em detrimento de modelos de Democracia de Projetos. ${ }^{35}$

Mas é possível afastarmos definitivamente os riscos e perigos que ameaçam os regimes democráticos de exercício do político e da política? Temos que não, diante mesmo do reconhecimento de que as tensionalidades e conflitos próprios de nosso quotidiano não estão a revelar total fracasso do projeto da Modernidade de liberdade, igualdade e fraternidade, mas sim que tais ambientes conturbados são decorrentes de correlações de forças e sujeitos não totalmente controláveis ou ajustáveis àquelas promessas (por múltiplas razões), reclamando, por isto, esforços constantes de todos à regeneração dos pactos civilizatórios e de suas efetividades.

A lição de Rosanvallon é curial aqui, no sentido de termos presente que a Democracia historicamente se manifesta como promessa e problema: enquanto promessa, afigura-se como regime de governo de acordo com as necessidades sociais fundadas sobre a realização de duplo imperativo, o da igualdade e o da autonomia; enquanto problema, tem-se mostrado sempre muito longe de satisfazer suas promessas, extraindo daí sua força utópica e regulativa. ${ }^{36}$

De qualquer sorte, aceitarmos que constitui esta Democracia momentos de imprevisibilidade de suas possibilidades, notadamente em face de situações de excessão, implica reconhecer, com Clinton Rossiter, a importância de permanentemente monitorarmos, preventiva e curativamente, aquelas situações inimagináveis, potencializadoras de instabilidades democráticas, através de blocos normativos diferidos, distinguindo o uso do puro arbítrio velado pela urgência da ação política, das ações politicas de emergência vinculadas constitucional e infraconstitucionalmente. ${ }^{37}$

\section{REFERÊNCIAS}

AGAMBEN, Giorgio. Stato di eccezione. Homo sacer, II, I. Torino: Bollati Boringhieri editore, 2003.

ARISTÓTELES. Politics. New York: Basic Books, 2000.

34 Ver os textos de LEFORT, Claude. Essai sur la politique. Paris: Seuil, 1986, e ROSANVALLON, Pierre. La crise de l'état-providence. Paris: Le Seuil, 1981.

35 ROSANVALLON, Pierre. Le contre-démocratie: la politique à l'âge de la défiance. Op.cit.

36 Idem, p.24.

37 Ver o texto de ROSSITER, Clinton L. Constitutional Dictatorship - crisis government in the modern democracies. London: Princeton University, 2000. 
ARROW, Kenneth J. The limits of organization. New York: Norton, 1974.

BARBIERI, Maria Stella. Il senso del politico. Saggio su Carl Schmitt. Milano: Giuffrè, 1990.

BEAUD, Oliver. La potenza dello Stato. Napoli: Edizioni Scientifiche Italiane, 2002.

CEDRONIO, Marina (ed.). Modernité, Démocratie et Totalitarisme: Simone Weil et Hannah Arendt. París: Klincksieck, 1996.

CHEVALIER, Jacques. O Estado Posmoderno. Bogotá: Universidad Externado, 2015.

CILIBERTO, Michele. La Democrazia Dispotica. Roma-Bari: Laterza, 2011.

DYZENHAUS, David. Legality and Legitimacy: Carl Schmitt, Hans Kelsen and Hermann Heller in Weimar. Oxford \& New York: Oxford University Press, 1997.

FOUCAULT, Michel. Verdad y Poder. Obras esenciales. Madrid: Paidós, 2010.

GALLI, Carlo. Genealogia della politica: Carl Schmitt e la crisi del pensiero politico moderno. Bologna: Mulino, 1996.

GRABER, David. Occupy Democracy is not considered newsworthy. It should be. In https://www.theguardian.com/commentisfree/2014/oct/27/occupydemocracy-london-parliament-square, acesso em 14/08/2018.

HABERMAS, Jürgen. Su concetto di partecipazione politica. Roma: Daltrice, 2000.

http://politica.estadao.com.br/blogs/coluna-do-estadao/empresarios-pedem-e300-militares-ja-dirigem-caminhoes-privados/, acesso em 29/05/2018.

http://www.gazetadopovo.com.br/politica/republica/decreto-deglo-autoriza-uso-de-militares-contra-greve-dos-caminhoneiros4qi15m8d1uhik8ydnd6e00zzz, acesso em 01/06/2018.

https://gauchazh.clicrbs.com.br/ultimas-noticias/tag/greve-dos-caminhoneiros/, acesso em 29/05/2018.

https://www12.senado.leg.br/noticias/materias/2018/05/28/congresso-recebemedidas-provisorias-do-acordo-do-governo-com-caminhoneiros, acesso em 01/06/2018.

JIMÉNEZ, Gretty Del Carmen Pavlovich. El estado de excepción: la tensión entre la política y el derecho. In Justicia Juris, ISSN 1692-8571, Vol 10. Octubre 2008 - Marzo 2009. 
KELSEN, Hans. Dio e Stato. La giurisprudenza come scienza dello spirito. Roma: Edizioni Scientifiche Italiane, 1988.

----. Il problema della sovranità e teoria del diritto internazionale. Contributo per una dottrina pura del diritto. Milano: Giuffrè, 1989.

LEFORT, Claude. Essai sur la politique. Paris: Seuil, 1986.

LIMONGI, Fernando e FIGUEIREDO, Argelina. Bases institucionais do Presidencialismo de Coalizão. In Lua Nova, no 44, p. 81-106, 1998.

POCOCK, Jonh Arthur. Theorizing Citizenship. New York: State University of New York Press, 2004.

PREUSS, Urlich K. The ambiguous meaning of citizenship. Trabalho apresentado na University of Chicago Law School, no Center for Comparative Constitutionalism, em dezembro de 2006.

RIESENBERG, Peter. Citizenship in the Western Tradition. Plato to Rousseau. Chapel Hill/London: The University of North Carolina Press, 2000.

ROSANVALLON, Pierre. La crise de l'état-providence. Paris: Le Seuil, 1981.

----. Le contre-démocratie: la politique à l'âge de la défiance. Paris: Le Seuil, 2006.

ROSSITER, Clinton L. Constitutional Dictatorship - crisis government in the modern democracies. London: Princeton University, 2000.

SCHMITT, Carl. La Dictadura. Madrid: Alianza Editorial, 1999.

----. Teologia Politica. In A crise da democracia parlamentar. São Paulo: Scritta, 1996.

TAYLOR, Alan John P. Bismarck: The Man and the Statesman. New York: Vintage Books, 1967.

WALZER, Michael. Thinking Politically: essays in political theory. New York: Vail Ballou Press, 2007.

Recebido em: 11/03/2019. Aprovado em: 05/08/2019. 